\title{
Granulomatous Mastitis with Erythema Nodosum That Responded to Low-Dose Steroid: Case Report and Literature Review of Nine Patients
}

\author{
Midori Noma, Ohara Masahiro, Kazuo Matsuura, Toshiyuki Itamoto \\ Breast Surgery, Hiroshima Prefectural Hospital, Hiroshima, Japan \\ Email: kimidori@mui.biglobe.ne.jp
}

Received 4 May 2014; revised 3 June 2014; accepted 1 July 2014

Copyright (C) 2014 by authors and Scientific Research Publishing Inc. This work is licensed under the Creative Commons Attribution International License (CC BY). http://creativecommons.org/licenses/by/4.0/

\begin{abstract}
A 31-year-old woman was referred with a painful mass in the left breast that was initially treated with antibiotics. Three weeks later, the mass had increased and polyarthritis and erythema nodosum had developed in both legs. A core needle biopsy led to a diagnosis of granulomatous mastitis with arthritis and erythema nodosum. Low-dose prednisolone $(10 \mathrm{mg})$ rapidly improved the arthritis and the erythema nodosum. Granulomatous mastitis is a very rare, chronic inflammatory disease and only nine patients with granulomatous mastitis with erythema nodosum have been described. We reviewed the literature to determine the clinicopathological features and treatment of granulomatous mastitis. Appropriate diagnosis and steroid therapy should result in excellent outcomes.
\end{abstract}

Keywords

Granulomatous Mastitis, Erythema Nodosum, Low-Dose Steroid

\section{Introduction}

Granulomatous mastitis is a very rare, chronic inflammatory disease of the breast that is often difficult to distinguish from breast cancer. Although the underlying cause remains unknown, the histological findings and responsiveness to steroid therapy suggest that the disease is immune-mediated. Adams et al. first reported during 1987 that patients with granulomatous mastitis can occasionally develop systemic symptoms such as erythema nodosum [1]. 
Nine patients have been described since then including the present patient. Here we describe granulomatous mastitis associated with erythema nodosum and arthritis that responded to low-dose steroid therapy. We reviewed the literature and discuss the clinicopathological features and treatment of this disease.

\section{Case Report}

A 31-year-old woman was referred to our hospital with a chief complaint of a painful mass in the left breast. She had given birth once at 21 years of age and was under treatment with selective serotonin reuptake inhibitors (SSRI) for adjustment disorder. She had no history of taking contraceptives.

A physical examination revealed a firm mass of about $7 \mathrm{~cm}$ in the upper outer quadrant of the left breast. Ultrasonography revealed a low echoic mass of $70 \mathrm{~mm}$ with an indistinct border, along with several small masses that were believed to be microabscesses in the marginal region (Figure 1). Fine needle aspiration cytology revealed no malignant findings and antibiotics were prescribed to treat acute purulent mastitis. However, the patient's symptoms did not improve and three weeks later, the mass had increased to $10 \mathrm{~cm}$ and was surrounded with abscesses. Joint pain that appeared around this time slowly worsened and erythema nodosum appeared in both legs (Figure 2).

Blood findings were as follows: WBC, 19,300/ $\mu \mathrm{L}$; CRP, $6.1 \mathrm{mg} / \mathrm{dL}$; ASO, normal; antinuclear and anti-cystic citrullinated peptide (CCP) antibodies were negative; prolactin was normal and general bacterial cultures were negative. Computed tomography (CT) revealed swelling of the entire left breast with a heterogeneous contrast effect and abscesses throughout the breast. The lymph nodes were not swollen (Figure 3).

A core needle biopsy revealed infiltration with aggregated lymphocytes, particularly in the lobules, epithelioid cell proliferation and multinucleate giant cells (Figure 4). These findings indicated a diagnosis of granulomatous mastitis with arthritis and erythema nodosum. Oral administration of prednisolone (10 mg/day) rapidly improved the arthritis and erythema nodosum. The prednisolone was gradually tapered and was discontinued about three months later. Although a palpable 4-cm mass remained, the patient was free of systemic symptoms or re-

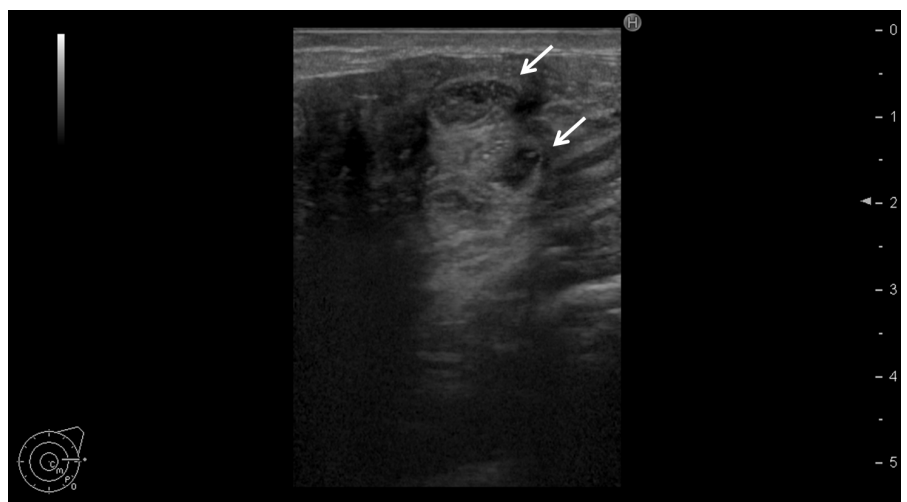

Figure 1. Ultrasound demonstrating hypoechoic mass lesion consisting of many small lesions (allow) in the left breast.

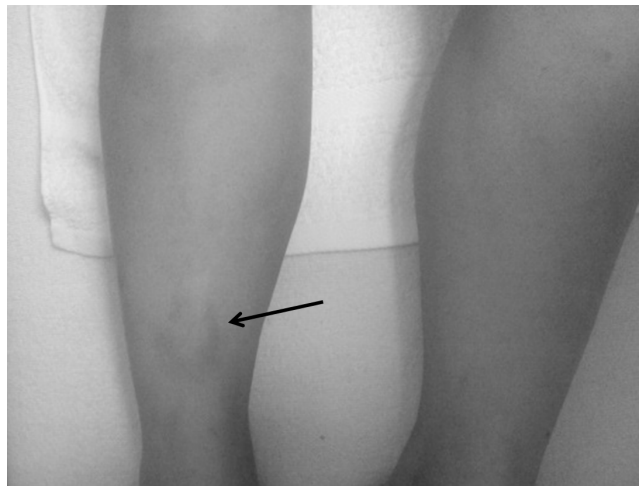

Figure 2. Erythema nodosum in the lower legs. 


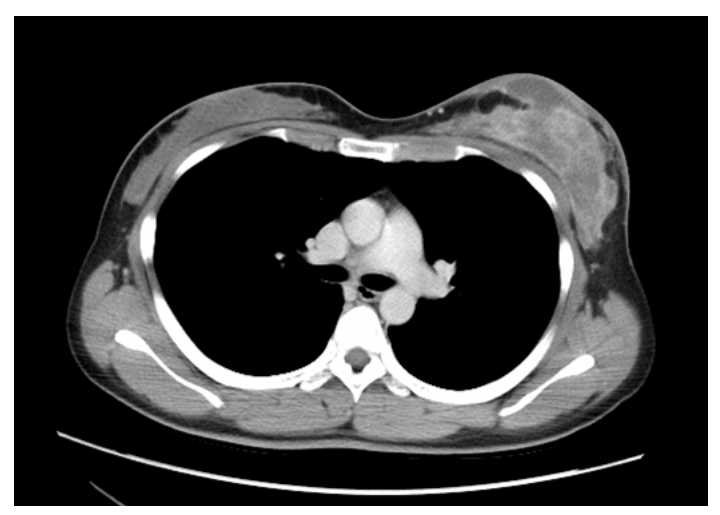

Figure 3. CT showing heterogeneous enhanced swelling breast tissue and abscess formation.

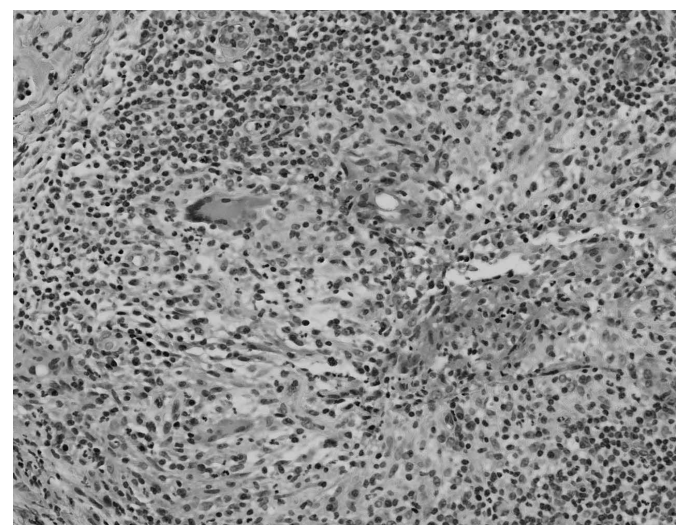

Figure 4. A core needle biopsy showing infiltration with aggregated lymphocyte and multinucleate giant cells.

current breast inflammation.

\section{Discussion}

Granulomatous mastitis is a very rare disease that was originally reported by Kessler and Wolloch et al. in 1972 [2]. It is a refractory inflammatory disease of the breast that is characterized by inflammatory cell infiltration and histiocytes with multinucleate giant cells [3]. It presents with a unilateral breast lump, breast pain and axillary lymph node swelling and is thus often difficult to distinguish from breast cancer [1] [2] [4] [5]. Only a histopathological examination of breast lesions can establish a definitive diagnosis. The disease commonly develops in women aged in their $20 \mathrm{~s}$ and $30 \mathrm{~s}$, two to three years after pregnancy, in those who have taken oral contraceptives, and in those with hyperprolactinemia (suggesting a syndrome involving lactation) [3]. Moreover, although some studies argue that the disease can be triggered by infection, trauma or perhaps a deeply involved immunological mechanism, the underlying cause remains unknown [2] [6] [7].

Only nine patients with granulomatous mastitis complicated by erythema nodosum have been reported (Table 1). Although the etiology of the comorbidity of these two conditions is unclear, they might have developed concurrently. Furthermore, granulomatous mastitis probably develops first and negative blood findings indicating the absence of an autoimmune state suggest that the erythema nodosum is a secondary reaction to the granulomatous mastitis or an extramammary lesion [1] [3] [8]-[13]. Considering the literature reports, erythema nodosum occurred relatively early in the disease progression and the granulomatous mass was large. Therefore, we believe that granulomatous mastitis progresses more rapidly and with a greater degree of inflammation when erythema nodosum is involved.

Steroids and drainage are commonly administered to treat granulomatous mastitis [14]-[18]. Several reports 
Table 1. Review of cases of GM with EN in literature.

\begin{tabular}{|c|c|c|c|c|c|}
\hline Source, years & Age, years & $\begin{array}{c}\text { Period from GM to } \\
\text { EN, weeks }\end{array}$ & $\begin{array}{c}\text { Other } \\
\text { symptoms }\end{array}$ & Tumor size, cm & Treatment \\
\hline Adams, 1987 & 23 & 14 & Arthritis & 12 & Symptomatic therapy \\
\hline Donn, 1994 & 36 & 7 & Unknown & 10 & PSL60 mg/day \\
\hline Olfatbakhsh, 2008 & 30 & 0 & Arthritis & 8 & PSL45 mg/day \\
\hline \multirow[t]{2}{*}{ Bes, 2009} & 34 & 8 & Unknown & 5 & PSL32 mg/day \\
\hline & 27 & 3 & Unknown & 8 & PSL32 mg/day \\
\hline Salesi, 2009 & 23 & 0 & Arthritis & Unknown & $\begin{array}{l}\text { PSL15 mg, cholchcine1mg, } \\
\text { AZA100 mg/day }\end{array}$ \\
\hline Nakamura, 2012 & 23 & 2 & Arthritis, Fever & 7 & $\begin{array}{c}\text { PSL40 mg/day } \\
\rightarrow \text { PSL50 mg/day, MTX4 } \\
\text { mg/week }\end{array}$ \\
\hline Binesh, 2013 & 40 & 6 & Arthritis, Fever & 8 & $\begin{array}{l}\text { DEX12 mg/day } \\
\rightarrow \text { PSL30 mg/day }\end{array}$ \\
\hline Present case & 31 & 4 & Arthritis, Fever & 10 & PSL10 mg/day \\
\hline
\end{tabular}

GM: granulomatous mastitis; EN: erythema nodosum; PSL: prednisolone; AZA: azathioprine; DEX: dexamethasone; MTX: methotrexate.

indicate that steroids rapidly ease systemic symptoms, whereas others describe that methotrexate prevents the recurrence of inflammation after steroid therapy [11] [19]. The reported patients were initially medicated with 30 - $60 \mathrm{mg} /$ day of prednisolone, whereas $10 \mathrm{mg} /$ day improved systemic symptoms in our patient. Because the condition can fall into spontaneous remission [1] [20], we believe that administering low-dose steroids from the time of diagnosis is effective.

\section{Conclusion}

Granulomatous mastitis rarely presents with systemic complications such as erythema nodosum. Appropriate diagnosis and steroid therapy results in excellent outcomes.

\section{References}

[1] Adams, D.H., Hubscher, S.G. and Scott, D.G. (1987) Granulomatous Mastitis-A Rare Cause of Erythema Nodosum. Postgraduate Medical Journal, 63, 581-582. http://dx.doi.org/10.1136/pgmj.63.741.581

[2] Kessler, E. and Wolloch, Y. (1972) Granulomatous Mastitis: A Lesion Clinically Simulating Carcinoma. American Journal of Clinical Pathology, 58, 642-646.

[3] Donn, W., et al. (1994) Idiopathic Granulomatous Mastitis. A Report of Three Cases and Review of the Literature. Archives of Pathology Laboratory Medicine, 118, 822-825.

[4] Cakir, B., et al. (2002) Granulomatous Mastitis Mimicking Breast Carcinoma. The Breast Journal, 8, 251-252. http://dx.doi.org/10.1046/j.1524-4741.2002.08413.x

[5] Adamietz, B.R., et al. (2011) Differentiation between Phyllodes Tumor and Fibroadenoma Using Real-Time Elastography. Ultraschall in der Medizin, 32, E75-E79. http://dx.doi.org/10.1055/s-0031-1282024

[6] Diesing, D., et al. (2004) Granulomatous Mastitis. Archives of Gynecology and Obstetrics, 269, 233-236. http://dx.doi.org/10.1007/s00404-003-0561-2

[7] Paviour, S., et al. (2002) Corynebacterium Species Isolated from Patients with Mastitis. Clinical Infectious Diseases, 35, 1434-1440. http://dx.doi.org/10.1086/344463

[8] Al-Khaffaf, B.H., Shanks, J.H. and Bundred, N. (2006) Erythema Nodosum-An Extramammary Manifestation of Granulomatous Mastitis. The Breast Journal, 12, 569-570. http://dx.doi.org/10.1111/j.1524-4741.2006.00348.x

[9] Bes, C., et al. (2010) Erythema Nodosum Associated with Granulomatous Mastitis: Report of Two Cases. Rheumatology International, 30, 1523-1525. http://dx.doi.org/10.1007/s00296-009-1109-y

[10] Binesh, F., et al. (2013) Idiopathic Granulomatous Mastitis, Erythema Nodosum and Bilateral Ankle Arthritis in an Iranian Woman. BMJ Case Reports, 2013. 
[11] Nakamura, T., et al. (2012) Granulomatous Mastitis Complicated by Arthralgia and Erythema Nodosum Successfully Treated with Prednisolone and Methotrexate. Internal Medicine, 51, 2957-2960. http://dx.doi.org/10.2169/internalmedicine.51.7846

[12] Olfatbakhsh, A., Beheshtian, T. and Djavid, G.E. (2008) Granulomatous Mastitis, Erythema Nodosum, and Oligoarthritis in a Pregnant Woman. The Breast Journal, 14, 588-590. http://dx.doi.org/10.1111/j.1524-4741.2008.00653.x

[13] Salesi, M., et al. (2011) A Case of Granulomatous Mastitis with Erythema Nodosum and Arthritis. Rheumatology International, 31, 1093-1095. http://dx.doi.org/10.1007/s00296-009-1273-0

[14] Akcan, A., et al. (2006) Granulomatous Lobular Mastitis: A Complex Diagnostic and Therapeutic Problem. World Journal of Surgery, 30, 1403-1409. http://dx.doi.org/10.1007/s00268-005-0476-0

[15] Azlina, A.F., et al. (2003) Chronic Granulomatous Mastitis: Diagnostic and Therapeutic Considerations. World Journal of Surgery, 27, 515-518. http://dx.doi.org/10.1007/s00268-003-6806-1

[16] Hirata, S., et al. (2003) Granulomatous Mastitis Diagnosed by Core-Needle Biopsy and Successfully Treated with Corticosteroid Therapy: A Case Report. Breast Cancer, 10, 378-381. http://dx.doi.org/10.1007/BF02967662

[17] Lai, E.C., et al. (2005) The Role of Conservative Treatment in Idiopathic Granulomatous Mastitis. The Breast Journal, 11, 454-456. http://dx.doi.org/10.1111/j.1075-122X.2005.00127.x

[18] Taghizadeh, R., et al. (2007) Idiopathic Granulomatous Mastitis: Surgery, Treatment, and Reconstruction. The Breast Journal, 13, 509-513. http://dx.doi.org/10.1111/j.1524-4741.2007.00474.x

[19] Kim, J., Tymms, K.E. and Buckingham, J.M. (2003) Methotrexate in the Management of Granulomatous Mastitis. ANZ Journal of Surgery, 73, 247-249. http://dx.doi.org/10.1046/j.1445-1433.2002.02564.x

[20] Imoto, S., et al. (1997) Idiopathic Granulomatous Mastitis: Case Report and Review of the Literature. Japanese Journal of Clinical Oncology, 27, 274-277. http://dx.doi.org/10.1093/jico/27.4.274 
Scientific Research Publishing (SCIRP) is one of the largest Open Access journal publishers. It is currently publishing more than 200 open access, online, peer-reviewed journals covering a wide range of academic disciplines. SCIRP serves the worldwide academic communities and contributes to the progress and application of science with its publication.

Other selected journals from SCIRP are listed as below. Submit your manuscript to us via either submit@scirp.org or Online Submission Portal.
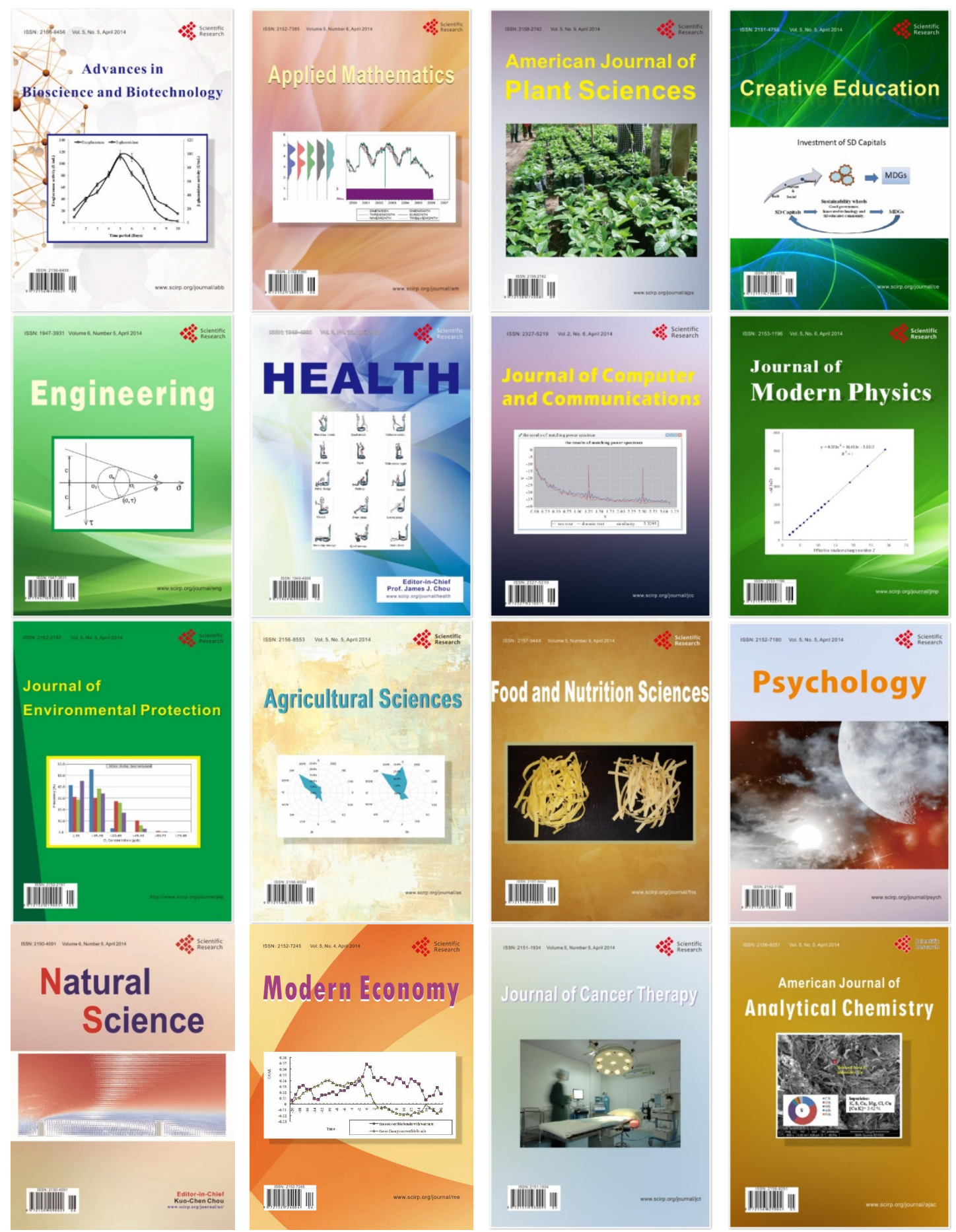